\title{
Modification of Treatment Strategies Over a Period of 14 Years Has Markedly Reduced Cardiac Events Among Post-Myocardial Infarction Patients
}

\author{
Kinji Ishikawa, MD; Akio Kimura, MD; Takaaki Taniwa, MD; \\ Toshihiko Takenaka, MD*; Takahiro Hayashi, MD; Ken Kanamasa, MD* \\ on behalf of the Secondary Prevention Group
}

\begin{abstract}
Recent trends in the treatment of post-myocardial infarction (MI) patients and the factors accounting for the improvement in outcome are presented. A total of 6,602 post-MI patients $(5,320$ males, 1,282 females; $58.9 \pm 10.4$ years of age) enrolled between 1986 and 1999 were followed up for an average of $12.6 \pm 16.3$ months. The incidence of cardiac events, which included fatal and nonfatal recurrent MIs, sudden death and death by congestive heart failure, was highest (44.9 events/1,000 person ·year) in 1986-1987, but decreased steadily to 22.5 events/1,000 person - year by 1997-1999 (Trend $p<0.0001$ ). This trend accompanied the increased use of coronary thrombolysis, percutaneous transluminal coronary angioplasty and coronary artery bypass graft surgery, increased prescription of antiplatelet agents $(51.5 \% \rightarrow 83.4 \%)$, lipid-lowering agents $(29.8 \% \rightarrow 52.6 \%)$ and angiotensin-converting enzyme inhibitors $(5.3 \% \rightarrow 41.0 \%)$, and reduced prescription of calcium antagonists $(68.5 \% \rightarrow 41.0 \%)$ and nitrates $(60.7 \% \rightarrow 45.7 \%)$. These changes in treatment have led to a decreased incidence of angina pectoris, wall motion abnormalities and abnormal $\mathrm{Q}$ waves on electrocardiograms. The decline in the incidence of cardiac events among post-MI patients in the 14 years between 1986 and 1999 reflects implementation of new therapeutic modalities proven to be effective in clinical trials and in daily practice. (Circ J 2002; 66: $881-885)$
\end{abstract}

Key Words: Cardiac events; Recurrent myocardial infarction; Secondary prevention

$\mathbf{T}$ he short-term prognosis of patients with acute myocardial infarction (MI) has been markedly improved by the introduction of reperfusion therapy: in Israel the 30-day hospital mortality among acute MI patients was reduced from $17.0 \%$ in the pre-reperfusion era of 19811983 to $10.8 \%$ in $1992-1994$, and the Minnesota Heart Survey also reported that 3-year mortality among 28-day survivors of acute myocardial infarction declined from 17 (person per 100,000) in 1985 to 13 in 1995 in men and from 22 to 11 in women? Investigating the trends in the treatment of MI among a population of 1.5 million patients entered in the National Registry of Myocardial Infarction in the United States, Rogers et al found that the use of $\beta$-blockers, aspirin and angiotensin-converting enzyme inhibitors (ACEI) increased over the period from 1990 to 1999, and hospital mortality declined from $11.2 \%$ to $9.4 \%$ during the same period? They concluded that the recommendations of recent clinical trials and published guidelines were indeed being implemented, resulting in more frequent use of therapies known to reduce mortality and diminished use of therapies, such as prescription of short-acting nifedipine, now known to be ineffective.

There has also been improvement in the long-term prognosis of post-MI patients. For example, among 2,733

(Received April 19, 2002; revised manuscript received June 3, 2002; accepted June 27, 2002)

Departments of Cardiology and *Vascular and Geriatric Medicine, Kinki University School of Medicine, Osakasayama, Japan

Mailing address: Kinji Ishikawa, MD, Professor of Medicine, Department of Cardiology, Kinki University School of Medicine, 377-2 Ohnohigashi, Osakasayama 589-8511, Japan. E-mail: ishikawa@ med.kindai.ac.jp
post-MI patients discharged from Japanese hospitals between 1983 and 1988, 172 (6.3\%) had recurrent MI during a mean follow-up period of 2.9 years. By contrast, the incidence of cardiac events, including recurrent MI, sudden death and death by congestive heart failure, among 1,483 Japanese post-MI patients discharged between 1986 and 1996 was $4.8 \%$ (33 events per 1,000 person -year) during a mean follow-up period of $17.4 \pm 20.9$ months 5 The purpose of the present study was to assess by how much the long-term prognosis in post-MI patients has been improved, what changes in treatment modality might account for this improvement, and what we can do to improve further the prognoses of these patients.

\section{Methods}

Subjects

A total of 6,602 post-MI patients treated in hospital were studied.

\section{Enrollment}

Subjects were consecutively enrolled in the study from January 1986 to December 1999, including all MI patients from the Department of Cardiology. The diagnosis of MI was based on history, electrocardiogram (ECG) changes and a significant elevation of myocardial serum enzymes. All inpatients with acute MI were registered after 8 days of onset; all outpatients with a healed MI were registered on their first visit to the Department. If a patient had a nonfatal recurrent MI and revisited the hospital, he/she was registered as a new patient upon return. If a patient visited another hospital but returned to the primary hospital for 
Table 1 Characteristics of the Post-Ml Patients in the 14 Years of the Study

\begin{tabular}{|c|c|c|c|c|c|c|}
\hline & $\begin{array}{c}1986-1987 \\
n=1,089\end{array}$ & $\begin{array}{c}1988-1990 \\
n=1,099\end{array}$ & $\begin{array}{c}1991-1993 \\
n=1,478\end{array}$ & $\begin{array}{c}1994-1996 \\
n=1,585\end{array}$ & $\begin{array}{c}1997-1999 \\
n=1,351\end{array}$ & $p$ value ${ }^{\dagger}$ \\
\hline Sex, male \% & 81.8 & 78.5 & 81.9 & 80.9 & 79.4 & \\
\hline Age, years & $59.5 \pm 11.6$ & $59.8 \pm 11.0$ & $58.5 \pm 10.1 *$ & $58.8 \pm 10.1$ & $58.3 \pm 9.7 * *$ & 0.0010 \\
\hline Mean observation period, months & $16.0 \pm 21.1$ & $15.0 \pm 19.5$ & $14.7 \pm 18.3$ & $10.4 \pm 11.2$ & $8.3 \pm 8.7 * * *$ & 0.0010 \\
\hline \multicolumn{7}{|l|}{ Blood pressure, $\mathrm{mmHg}$} \\
\hline Systolic & $128 \pm 22$ & $127 \pm 20$ & $125 \pm 19 * * *$ & $124 \pm 18 * * *$ & $126 \pm 18 *$ & 0.0001 \\
\hline Diastolic & $77 \pm 13$ & $75 \pm 12 * * *$ & $73 \pm 11 * * *$ & $73 \pm 11 * * *$ & $73 \pm 11 * * *$ & 0.0001 \\
\hline Heart rate, beats/min & $65 \pm 11$ & $65 \pm 11$ & $66 \pm 12$ & $67 \pm 11 * *$ & $66 \pm 12$ & 0.0170 \\
\hline \multicolumn{7}{|l|}{ Characteristics of first MI } \\
\hline Anterior wall infarction, $\%$ & 43.1 & $34.2 * * *$ & $38.4^{*}$ & 41.2 & 40.3 & \\
\hline Killip class, $1 \%$ & 81.4 & $88.3 * * *$ & 82.5 & 83.4 & $87.5 * * *$ & \\
\hline Number of involved vessels, $1 \mathrm{VD} \%$ & 41.0 & 43.2 & $45.1 *$ & 44.6 & $46.5 *$ & \\
\hline Peak $C K, U / L$ & $2,415 \pm 2,073$ & $2,489 \pm 2,095$ & $2,638 \pm 2,165 * *$ & $2,810 \pm 2,307 * * *$ & $2,952 \pm 2,430 * * *$ & 0.0001 \\
\hline \multicolumn{7}{|l|}{ Interventional therapy } \\
\hline Coronary thrombolysis, \% & 27.8 & $33.2 * *$ & $42.8^{* * * *}$ & $48.2 * * *$ & 45.6 *** & 0.0001 \\
\hline PTCA, \% & 4.2 & $17.5 * * *$ & $27.2^{* * * *}$ & $36.0^{* * *}$ & $45.6^{* * * *}$ & 0.0001 \\
\hline$C A B G, \%$ & 1.9 & $5.7 * * *$ & $7.7 * * *$ & $13.5 * * *$ & $16.6^{* * *}$ & 0.0001 \\
\hline Wall motion index by echocardiogram & $8.7 \pm 6.0$ & $8.2 \pm 5.7$ & $6.7 \pm 5.6^{* * *}$ & $6.9 \pm 5.2 * * *$ & $6.4 \pm 5.1 * * *$ & 0.0001 \\
\hline ECG QRS score & $6.1 \pm 4.0$ & $5.1 \pm 3.5^{* * *}$ & $5.1 \pm 3.5^{* * *}$ & $4.5 \pm 3.6^{* * *}$ & $4.6 \pm 3.5 * * *$ & 0.0001 \\
\hline Post-MI angina, $\%$ & 37.3 & 33.5 & $28.8 * * *$ & $22.2 * * *$ & $14.0 * * *$ & 0.0001 \\
\hline \multicolumn{7}{|l|}{ Coronary risk factors, $\%$} \\
\hline Hyperlipidemia & 53.8 & 50.3 & 50.8 & 52.3 & 51.5 & \\
\hline Hypertension & 45.2 & 49.2 & 45.8 & $49.8 * *$ & 48.9 & \\
\hline Smoking including ex-smokers & 63.9 & 67.8 & $71.4 * * *$ & $73.9 * * *$ & $70.6^{* * *}$ & 0.0001 \\
\hline Diabetes mellitus & 27.1 & 29.3 & 26.7 & 30.1 & 29.8 & \\
\hline Obesity & 16.0 & $22.6^{* * *}$ & $25.9 * * *$ & $31.7 * * *$ & $30.3 * * *$ & 0.0001 \\
\hline \multicolumn{7}{|l|}{ Laboratory findings during follow-up } \\
\hline Total cholesterol, $\mathrm{mg} / \mathrm{dl}$ & $214 \pm 43$ & $206 \pm 40 * * *$ & $197 \pm 37 * * *$ & $194 \pm 36 * * *$ & $199 \pm 34 * * *$ & 0.0001 \\
\hline Triglycerides, $\mathrm{mg} / \mathrm{dl}$ & $163 \pm 94$ & $181 \pm 118 * * *$ & $153 \pm 95 * *$ & $147 \pm 87 * * *$ & $152 \pm 80 * *$ & 0.0001 \\
\hline HDL cholesterol, $\mathrm{mg} / \mathrm{dl}$ & $41 \pm 13$ & $41 \pm 13$ & $44 \pm 12 * * *$ & $42 \pm 12 *$ & $41 \pm 12$ & 0.0001 \\
\hline Positive exercise ECG test, \% & 37.1 & $46.6 * * *$ & $40.9 *$ & $42.7^{*}$ & $31.2 * *$ & \\
\hline \multicolumn{7}{|l|}{ Drug treatment, $\%$} \\
\hline Antiplatelet agents & 51.5 & $62.8 * * *$ & $72.7 * * *$ & $78.9 * * *$ & $83.4 * * *$ & 0.0001 \\
\hline Lipid-lowering agents & 29.8 & $33.8^{*}$ & $41.7 * * *$ & $45.2 * * *$ & $52.6 * * *$ & 0.0001 \\
\hline$A C E I$ & 5.3 & $11.4 * * *$ & $23.3 * * *$ & $34.8^{* * *}$ & $41.0 * * *$ & 0.0001 \\
\hline$\beta$-blockers & 53.4 & $64.5^{* *}$ & $63.1 * * *$ & $61.7 * * *$ & $60.4 * * *$ & 0.0001 \\
\hline Warfarin & 23.1 & 26.4 & $34.4^{* * * *}$ & $27.4^{*}$ & $16.3^{* * *}$ & \\
\hline Calcium antagonists & 68.5 & $59.1 * * *$ & $48.0^{* * *}$ & $41.5^{* * *}$ & $41.0 * * *$ & 0.0001 \\
\hline Nitrates & 60.7 & $69.3 * * *$ & $68.9^{* * *}$ & $54.8^{* *}$ & $45.7 * * *$ & 0.0360 \\
\hline Antiarrhythmic agents & 8.6 & 10.6 & 9.8 & 8.9 & 8.1 & \\
\hline
\end{tabular}

Mean \pm standard deviation.

MI, myocardial infarction; IVD, one vessel disease; CK, serum creatine kinase activity; PTCA, percutaneous transluminal coronary angioplasty; CABG, coronary artery bypass graft surgery; ACE I, angiotensin converting enzyme inhibitors.

Difference between 1986, 1987. *p<0.05, **p<0.01, ***p<0.001.

The Mantel-Haenszel test assessed trends by serial time intervals over the duration of the registry.

any reason, the earlier and later observations were registered separately. Likewise, if a patient had coronary artery bypass graft surgery or percutaneous transluminal coronary angioplasty, observations made before and after those procedures were registered separately, If there were any changes in the prescription of one or more of the antiplatelet agents, lipid-lowering agents, ACEI, $\beta$-blockers, warfarin, calcium antagonists, nitrates or antiarrhythmic agents, observations made before and after administration of the new medications were registered separately.

\section{Follow-up Examination}

Serial blood tests, exercise ECGs, and echocardiography were carried out several times for hospitalized patients and approximately twice a year for outpatients. Left ventricular wall motion abnormality was evaluated using echocardiography according to Heger et al6 QRS scores on ECGs were calculated as an index related to infarct size according to Wagner et al? Hyperlipidemia was considered to be present if the patient had a past history of total cholesterol $>220 \mathrm{mg} / \mathrm{dl}$ and a history of hypertension was defined as casual systolic blood pressure $>160 \mathrm{mmHg}$ or diastolic pressure $>95 \mathrm{mmHg}$. Obesity was considered to be present if patients had a body mass index $>25$.

\section{Exclusion and Lost-to-Follow}

Because the present study focused on the long-term prognoses of patients with healed MI, cardiac events occurring within 7 days of onset of symptoms were excluded. If a patient ceased visiting the hospital, efforts were made to contact him/her by telephone and determine the reason so as to avoid overlooking cardiac or other medical events. Those patients who stopped coming in for unknown reasons and whom we failed to contact were defined as lost-tofollow.

\section{Primary End-Points}

The primary end-points were cardiac events, which included fatal and nonfatal recurrent MI, sudden death and death by congestive heart failure. 
Table 2 Cardiac Events in Post-MI Patients in the 14 Years of the Study

\begin{tabular}{|c|c|c|c|c|c|c|c|}
\hline & $\begin{array}{c}1986-1987 \\
n(\%)\end{array}$ & $\begin{array}{c}1988-1990 \\
n(\%)\end{array}$ & $\begin{array}{c}1991-1993 \\
n(\%)\end{array}$ & $\begin{array}{c}1994-1996 \\
n(\%)\end{array}$ & $\begin{array}{c}1997-1999 \\
n(\%)\end{array}$ & $p$ value $^{\dagger}$ & $\begin{array}{c}\text { All } \\
n(\%)\end{array}$ \\
\hline & $n=1,089$ & $n=1,099$ & $n=1,478$ & $n=1,585$ & $n=1,351$ & & $n=6,602$ \\
\hline \multicolumn{8}{|l|}{$R e-M l$} \\
\hline Fatal & $9(0.8 \%)$ & $8(0.7 \%)$ & $5(0.3 \%)$ & $4(0.3 \%)$ & $4(0.3 \%)$ & 0.0340 & $30(0.5 \%)$ \\
\hline Nonfatal & $42(3.9 \%)$ & $21(1.9 \%) * *$ & $28(1.9 \%) * *$ & $16(1.0 \%) * * *$ & $10(0.7 \%) * * *$ & 0.0001 & $117(1.8 \%)$ \\
\hline Sudden death & $12(1.1 \%)$ & $9(0.8 \%)$ & $7(0.5 \%)$ & $2(0.1 \%) * * *$ & $3(0.2 \%) * *$ & 0.0010 & $33(0.5 \%)$ \\
\hline Death by $\mathrm{CHF}$ & $2(0.2 \%)$ & $3(0.3 \%)$ & $5(0.3 \%)$ & $1(0.1 \%)$ & $4(0.3 \%)$ & & $15(0.2 \%)$ \\
\hline Total (cardiac events) & $65(6.0 \%)$ & $41(3.7 \%)^{* *}$ & $45(3.0 \%) * * *$ & $23(1.5 \%) * * *$ & $21(1.6 \%) * * *$ & 0.0001 & $195(3.0 \%)$ \\
\hline$<$ events/1,000 person $\cdot$ year $>$ & $<44.9>$ & $<29.8>* *$ & $<24.8>* *$ & $<16.7>* *$ & $<22.5>* *$ & 0.0001 & $<28.1>$ \\
\hline Non-cardiac death & $27(2.5 \%)$ & $31(2.8 \%)$ & $21(1.4 \%) *$ & $19(1.2 \%) * *$ & $4(0.3 \%) * * *$ & 0.0020 & $102(1.5 \%)$ \\
\hline Total mortality & $50(4.6 \%)$ & $51(4.6 \%)$ & $38(2.6 \%) * *$ & $26(1.6 \%) * * *$ & $15(1.1 \%) * * *$ & 0.0001 & $180(2.7 \%)$ \\
\hline Lost-to-follow-up & $6(0.6 \%)$ & $4(0.4 \%)$ & $4(0.3 \%)$ & $12(0.8 \%)$ & $4(0.3 \%)$ & & $30(0.5 \%)$ \\
\hline
\end{tabular}

Re-MI, recurrent myocardial infarction; $C H F$, congestive heart failure.

${ }^{*} p<0.05, * * p<0.01, * * * p<0.001$ vs 1986, 1987.

tThe Mantel-Haenszel test assessed trends by serial time intervals over the duration of the registry.

\section{Statistical Analysis}

Data are presented as means \pm one standard deviation. For categoric data, the Mantel-Haenszel chi-square test was used as the measure of trends? Differences between 2 values were tested using the ${ }^{2}$ test. Two-sided probability values are presented; values of $p<0.05$ were considered significant.

\section{Results}

\section{Study Population}

During the 14 -year study period, a total of 6,602 post-MI patients (5,320 males, 1,282 females; mean age, 58.9 \pm 10.4 years at onset) were registered. The mean time from onset of symptoms to registry was $34.4 \pm 42.5$ months, and the mean observation period was $12.6 \pm 16.3$ months. Patients were grouped in 5 time periods as shown in Table 1. Peak serum creatine kinase activity after the first MI was higher among patients enrolled during 1997-1999, and more of those patients were treated with coronary thrombolysis, percutaneous transluminal coronary angioplasty and coronary artery bypass graft surgery than in earlier periods. Among patients with multivessel disease, $4.2 \%$ had bypass surgery in 1986-1987; this increased to $10.2 \%$ in $1988-1990,13.5 \%$ in $1991-1993,24.0 \%$ in $1994-1996$ and $28.2 \%$ in $1997-1999$. The incidence of wall motion abnormalities and QRS scores on ECGs declined over the course of the study period, as did the incidence of angina pectoris.

\section{Coronary Risk Factors}

During 1986-1987, 386 patients reported a history of hypertension; their mean blood pressure was $138 \pm 23$ $180 \pm 14 \mathrm{mmHg}$. During 1997-1999, 625 patients reported a history of hypertension; in this group, the mean blood pressure was $130 \pm 18 / 75 \pm 11 \mathrm{mmHg}$, whereas in those with no history of it was $122 \pm 17 / 70 \pm 11 \mathrm{mmHg}$. Among the former group of patients, both systolic and diastolic blood pressures were significantly $(\mathrm{p}<0.01)$ lower in $1997-1999$ than in 1986-1987. The percentage of smokers, including exsmokers, remained high throughout the study period. There were 232 diabetic patients enrolled during 1986-1987 and 384 during 1997-1999. Hemoglobin A1c $(8.3 \pm 2.9$ vs 6.8 $\pm 1.1: \mathrm{p}<0.01)$ and total cholesterol $(218 \pm 46$ vs $199 \pm 36 \mathrm{mg} / \mathrm{dl}: \mathrm{p}<0.01$ ) were both significantly lower in 1997-1999 than in 1986-1987. On the other hand, the inci-
Reduction of cardiac events and trends in drug use in these 14 years

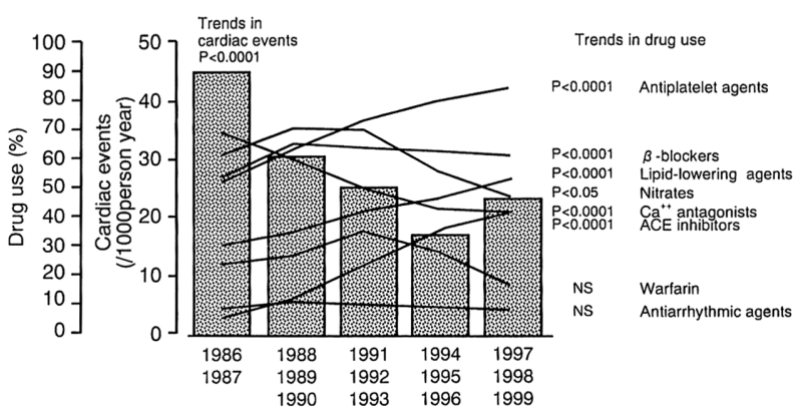

Fig 1. Reduction in cardiac events and trends in drug use in the 14 years of the study.

dence of obesity trended upward, nearly doubling over the course of the study period.

\section{Laboratory Findings}

Laboratory findings showed no remarkable changes over the course of the study period, though total cholesterol trended downward. During 1986-1987, 465 patients reported a history of hyperlipidemia: the mean total cholesterol was $236 \pm 41 \mathrm{mg} / \mathrm{dl}$ and $14.0 \%$ were taking statins. In 1997-1999, by contrast, 653 patients reported a history of hyperlipidemia: total cholesterol was $211 \pm 35 \mathrm{mg} / \mathrm{dl}$ ( $\mathrm{p}<$ 0.01 vs $1986-1987)$, and $89.5 \%$ were on statins.

\section{Trends in Drug Treatment}

Drug treatment showed a marked shift toward antiplatelet agents over the course of the study period, with $51.5 \%$ of patients receiving antiplatelet agents in 1986-1987 vs 83.4\% in 1997-1999. During 1986-1987 aspirin alone was taken by only $2.0 \%$ of patients, but aspirin combined with other antiplatelet agents was taken by $48.1 \%$ of patients. During 1997-1999, however, 49.8\% of patients took aspirin alone, and combined use had declined to $39.5 \%$. The use of warfarin also reduced during this period. Prescription of lipid-lowering agents increased over the years from $29.8 \%$ to $52.6 \%$, with $80.5 \%$ of those prescribed during 1997-1999 being statins. Use of ACEI also increased, and $\beta$-blockers were used consistently in more than half of post-MI patients (53.4-64.5\%), and among the 1,854 patients who were 65 years or older at onset, 1,005 (54.2\%) were prescribed $\beta$ - 
blockers. Use of calcium antagonists trended downward, as did that of nitrates, though they were still taken by $41.0 \%$ and $45.7 \%$ of patients, respectively, during 1997-1999. Antiarrhythmic agents were used in a limited number of patients.

\section{Trends in Cardiac Events (Table 2, Fig 1)}

Among the 6,602 post-MI patients, 195 cardiac events were recorded over the course of the study period $(3.0 \%$, 28.1 events/1,000 person -year). There was no statistical difference between the number of cardiac events occurring in males and females: 159 cardiac events $(3.0 \%, 27.6$ events $/ 1,000$ person year) among the 5,320 male patients and 36 events $(2.8 \%, 30.3$ events $/ 1,000$ person $\cdot$ year) among the 1,282 female patients. There were 78 cardiac deaths $(1.2 \%$, 11.2 events/1,000 person -year) and 147 recurrent MIs $(2.2 \%, 21.2$ events/1,000 person - year). There was a downward trend in the incidence of post-MI cardiac events throughout the study period, with the number of cardiac events declining from 44.9 events $/ 1,000$ person year in 1986-1987 to 22.5 events/1,000 person - year in 1997-1999 $(\mathrm{p}<0.01)$.

\section{Discussion}

\section{Recent Decline in Cardiac Events in Post-MI Patients}

According to the Framingham Study published in 1993 , following a first MI, there were 68.4 coronary deaths and 39 recurrent MIs per 1,000 person -year among males and 110.6 coronary deaths and 42.2 recurrent MIs per 1,000 person-year among females during a 34-year follow-up from 1948 to 1981 (no gender difference). This was substantially higher than the 11.2 cardiac deaths and 21.2 recurrent MIs per 1000 person -year observed during the 14-year period evaluated in the present study and is likely the result in part to differences in race and community. In addition, the Framingham Study was initiated and ended many years before the present study, suggesting that improved health habits and better treatment modalities also contributed to the observed improvement in the long-term prognosis of post-MI patients.

\section{Successful Use of Reperfusion Therapies}

The risk factors that affect clinical outcome following acute MI are multifactorial, so it is difficult to identify any single factor contributing to the improvement in the outcome for post-MI patients shown in the present study. Nevertheless, one would expect limitation of infarct size by myocardial salvage and preservation of left ventricular function to be major determinants affecting patient prognosis. For instance, in 1986-1987 only $27.8 \%$ of patients received coronary thrombolysis at the onset of symptoms; this increased to $45.6 \%$ by 1997-1999. In Japan, we used urokinase as a thrombolytic agent in 1985; tissue-type plasminogen activator (tPA), which gave a higher rate of reperfusion was adopted in 1991, and then in 1998 mutant tPA became available. Reduction of wall motion abnormalities and QRS scores on the ECG may reflect the successful use of such reperfusion therapy during the acute phase. There has also recently been a tremendous increase in the number of patients receiving percutaneous transluminal coronary angioplasty or coronary artery bypass graft surgery. In particular, bypass surgery in cases of multivessel disease may have contributed much to the improved long-term prognosis. With the use of such interventional therapy, the incidence of post-MI angina pectoris has been reduced by more than half. However, only $28.2 \%$ of patients with multivessel disease in the present study population received bypass surgery and we would encourage greater use of this technique.

\section{Effective Secondary Prevention of MI}

Accumulating evidence is clarifying which drugs are effective for secondary prevention of MI and which are not 910 In that regard, randomized clinical trials have had a measurable influence on the patterns of medical practice. For example, in 1994 the Antiplatelet Trialists Collaboration concluded that with respect to every category of highrisk patient, antiplatelet therapy was definitely protective ${ }^{11}$ In addition, Stafford reported that aspirin use among outpatients with coronary artery disease in the United States increased from $5.0 \%$ of patients in 1980 to $26.6 \%$ in $1996 !^{2}$ In the present study population, aspirin was used more in 1997-1999, possibly encouraged by the results, which showed aspirin $(50 \mathrm{mg} /$ day) plus either dipyridamole $(150 \mathrm{mg} /$ day $)$ or ticlopidine $(200 \mathrm{mg} /$ day $)$ was effective in preventing recurrent $\mathrm{MI}^{13}$ Based on convincing evidence that lowering serum lipid is effective at preventing cardiac events, ${ }^{14} 52.6 \%$ of patients were taking lipid-lowering agents (mostly statins) by 1997-1999. ACEI are effective in patients following MI, particularly those with the signs and symptoms of heart failure or with chronic left ventricular dysfunction? Consistent with those findings, we also found that increased use of ACEI likely contributes to improved long-term prognosis. The important role of $\beta$ blockers for secondary prevention of MI has been pointed out repeatedly ${ }^{15,16}$ but their use is limited, especially among elderly patients. ${ }^{77}$ Use of $\beta$-blockers in our study population was high compared with that described by Heller et al, who reported that the use of $\beta$-blockers among elderly survivors of acute MI ( $>65$ years of age) increased from $39.6 \%$ in 1994 to $58.6 \%$ in 199718 Based in part on the recent evidence indicating the efficacy of $\beta$-blockers in preventing cardiac events, ${ }^{19}$ their use at our institution is relatively high, even among elderly patients, and still higher (71-72\%) usage of $\beta$-blockers in post-MI patients has been reported in Finland and Sweden ${ }^{20}$ Warfarin is effective for prevention of thrombotic events in some patients, and antiarrhythmic agents were used in a selected group within the study population.

Despite the availability of new types of calcium antagonists ${ }^{21}$ their use has been declining, possibly because of reports that indicated them to be ineffective at preventing secondary MI ${ }^{22,23}$ In addition, GISSI- $3^{24}$ and ISIS- 425 have both shown that long-term use of nitrates does not reduce mortality in post-MI patients; indeed studies from Japan ${ }^{26,27}$ indicate long-term use of nitrates may even be deleterious. Although, we found a slight decline in the use of nitrates since $1986,45.7 \%$ of patients were still taking nitrates in 1997-1999. Among elderly survivors of acute MI, 74.8$76.5 \%$ are reportedly taking nitrates and other vasodilators ${ }^{18}$ and Rogers et al found that approximately $30 \%$ of patients are discharged with nitrates? A randomized trial to evaluate long-term nitrate use in coronary artery disease would thus seem warranted.

\section{Coronary Risk Factors}

Approximately half the present patients had high serum total cholesterol or a history of hyperlipidemia. Mean total cholesterol declined from approximately $214 \mathrm{mg} / \mathrm{dl}$ in 
$1986-1987$ to $199 \mathrm{mg} / \mathrm{dl}$ in $1997-1999$, perhaps thanks to the increased use of statins. Blood pressure control is important to improve long-term prognosis in post-MI patients 28 Blood pressure was also lower in hypertensive patients in 1997-1999 than in 1986-1987, and among diabetic patients, hemoglobin A1c as well as total cholesterol was markedly lower during the same period. These positive findings among outpatients would be expected to have also contributed to the improved long-term prognosis. However, it was surprising how many post-MI patients have a history of smoking or are presently smokers, and there has been an increase the incidence of obesity among our patients. Perhaps additional patient education for reducing these coronary risk factors may further improve the long-term prognosis of post-MI patients.

\section{Study Limitation}

The results of the present study are drawn from post-MI patients at a single institution, and thus may not represent the national trend in Japan. To reach a national consensus on the proper advice for medical doctors and their patients, observations from many institutions in many districts will be needed.

\section{Conclusion}

There has been a marked decline in the incidence of cardiac events in post-MI patients during the 14 years of the study. The implementation of the findings of recent clinical trials and more use of therapies known to reduce cardiac events have contributed much to the improvement in long-term prognosis of these patients.

\section{References}

1. Gottlieb S, Goldbourt U, Boyko V, Harpaz D, Mandelzweig L, Khoury Z, et al. Mortality trends in men and women with acute myocardial infarction in coronary care units in Israel: A comparison between 1981-1983 and 1992-1994. Eur Heart J 2000; 21: $284-$ 295.

2. McGovern PG, Jacobs DR Jr, Shahar E, Arnett DK, Folsom AR, Blackburn H, et al. Trends in acute coronary heart disease mortality, morbidity, and medical care from 1985 through 1997: The Minnesota Heart Survey. Circulation 2001; 104: 19-24.

3. Rogers WJ, Canto JG, Lambrew CT, Tiefenbrunn AJ, Kindaid B, Shoultz DA, et al. Temporal trends in the treatment of over 1.5 million patients with myocardial infarction in the U.S. from 1990 through 1999: The National Registry of Myocardial Infarction 1,2 and 3. J Am Coll Cardiol 2000; 36: 2056-2063.

4. Hosoda S, Kimata S, Tamura K, Nakamura M, Toshima H, Shibata J, et al. Factors governing re-infarction in patients with myocardial infarction in Japan. Jpn Circ J 1995; 59: 130-136.

5. Ishikawa K, Kanamasa K, Hayashi T, Takenaka T, Inoki T, Katayama $\mathrm{K}$, et al. Drug treatment for secondary prevention of myocardial infarction. J Cardiol 2000; 35: 397-408.

6. Heger JJ, Weyman AE, Wann LS, Rogers EW, Dillon JC, Feigenbaum H. Cross-sectional echocardiographic analysis of the extent of left ventricular asynergy in acute myocardial infarction. Circulation 1980; 61: 1113-1118.

7. Wagner GS, Freye CJ, Palmeri ST, Roark SF, Stack NC, Ideker RE, et al. Evaluation of a QRS scoring system for estimating myocardial infarct size. I. Specificity and observer agreement. Circulation 1982; 65: $342-347$.

8. Cupples LA, Gagnon DR, Wong ND, Ostfeld AM, Kannel WB. Preexisting cardiovascular conditions and long-term prognosis after initial myocardial infarction: The Framingham Study. Am Heart $J$ 1993; 125: 863-872.

9. Wood D. European and American recommendations for coronary heart disease prevention. Eur Heart J 1998; 19(Suppl A): A12-A19.

10. Ryan TJ, Antman EM, Brooks NH, Califf RM, Hillis LD, Hiratzka LF, et al. 1999 Update: ACC/AHA guidelines for the management of patients with acute myocardial infarction: Executive summary and recommendations. A report of the American College of Cardiology /American Heart Association Task Force on practice guidelines (Committee on Management of Acute Myocardial Infarction). Circulation 1999; 100: 1016-1030.

11. Antiplatelet Trialists' Collaboration. Collaborative overview of randomised trials of antiplatelet therapy. I: Prevention of death, myocardial infarction, and stroke by prolonged antiplatelet therapy in various categories of patients. Br Med J 1994; 308: 81-106.

12. Stafford RS. Aspirin use is low among United States outpatients with coronary artery disease. Circulation 2000; 101: 1097-1101.

13. Ishikawa K, Kanamasa K, Hama J, Ogawa I, Takenaka T, Naito T, et al. Aspirin plus either dipyridamole or ticlopidine is effective in preventing recurrent myocardial infarction. Jpn Circ J 1997; 61: 38 45.

14. Scandinavian Simvastatin Survival Study Group. Randomised trial of cholesterol lowering in 4444 patients with coronary heart disease: The Scandinavian Simvastatin Survival Study (4S). Lancet 1994; 344: $1383-1389$.

15. Gottlieb SS, McCarter RJ, Vogel RA. Effect of beta-blockade on mortality among high-risk and low-risk patients after myocardial infarction. N Engl J Med 1998; 339: 489-497.

16. Ishikawa K, Miyataka M, Kanamasa K, Hayashi T, Takenaka T, Inoki $\mathrm{T}$, et al. Retrospective analysis showing less cardiac events in postmyocardial infarction patients treated with metoprolol. Jpn Circ J 2000; 64: 358-364.

17. Krumholz HM, Radford MJ, Wang Y, Chen J, Marciniak TA. Early $\beta$-blocker therapy for acute myocardial infarction in elderly patients. Ann Intern Med 1999; 131: 648-654.

18. Heller DA, Ahern FM, Kozak M. Changes in rates of $\beta$-blocker use between 1994 and 1997 among elderly survivors of acute myocardial infarction. Am Heart J 2000; 140: 663-671.

19. Ishikawa K, Miyataka M, Kanamasa K, Hayashi T, Takenaka T, Inoki $\mathrm{T}$, et al. $\beta$-blockers reduce the incidence of cardiac events in post-myocardial infarction patients. Jpn Heart J 2000; 41: 279-294.

20. Woods KL, Ketley D, Lowy A, Agusti A, Hagn C, Kala R, et al. The European Secondary Prevention Study Group. Beta-blockers and antithrombotic treatment for secondary prevention after acute myocardial infarction: Towards an understanding of factors influencing clinical practice. Eur Heart J 1998; 19: 74-79.

21. Lubsen J, Poole-Wilson PA, Pocock SJ, van Dalen FJ, Baumann J, Kirwan BA, et al. Design and current status of ACTION: A Coronary disease Trial Investigating Outcome with Nifedipine GITS. Eur Heart J 1998; 19(Suppl I): I20-I32.

22. Furberg CD, Psaty BM, Meyer JV. Nifedipine. Dose-related increase in mortality in patients with coronary heart disease. Circulation 1995; 92: 1326-1331.

23. Ishikawa K, Nakai S, Takenaka T, Kanamasa K, Hama J, Ogawa I, et al. Short-acting nifedipine and diltiazem do not reduce the incidence of cardiac events in patients with healed myocardial infarction. Circulation 1997; 95: 2368-2373.

24. Gruppo Italiano per lo Studio della Sopravvivenza nell'Infarto Miocardico. GISSI-3: Effects of lisinopril and transdermal glyceryl trinitrate singly and together on 6-week mortality and ventricular function after acute myocardial infarction. Lancet 1994; 343: $1115-$ 1122.

25. ISIS-4 (Fourth International Study of Infarct Survival) collaborative group. ISIS-4: A randomised factorial trial assessing early oral captopril, oral mononitrate, and intravenous magnesium sulphate in 58050 patients with suspected acute myocardial infarction. Lancet 1995; 345: 669-685.

26. Ishikawa K, Kanamasa K, Ogawa I, Takenaka T, Naito T, Kamata N, et al. Long-term nitrate treatment increases cardiac events in patients with healed myocardial infarction. Jpn Circ J 1996; 60: 779-788.

27. Nakamura Y, Moss AJ, Brown MW, Kinoshita M, Kawai C for the Multicenter Myocardial Ischemia Research Group. Long-term nitrate use may be deleterious in ischemic heart disease: A study using the databases from two large-scale postinfarction studies. Am Heart $J$ 1999; 138: $577-585$.

28. Wufuer M, Ishikawa K, Takenaka T, Kimura A, Hayashi T, Kanamasa K. Relationship between blood pressure and cardiac events in patients with a healed myocardial infarction. Jpn Circ J 2001; 65: 879-886. 